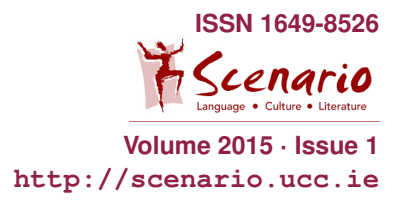

Window of Practice

\title{
Sounds in the Foreign Language Lesson
}

\author{
Philipp Botes
}

\begin{abstract}
Music and language are two worlds that are strongly interconnected. Psychological studies confirm that music is a very important part of the general learning process: music creates a positive climate in the classroom, lowers learners' affective filter, and reinforces semantic memory. Music is also particularly significant in language learning: music's rhythm facilitates memorisation of vocabulary, positively influences pronunciation and intonation, and reduces the perceived complexity of linguistic structures. Language, like music, is composed of sounds that require frequent training, not merely as an occasional entertaining activity but in a regular, daily lesson. The foreign language student needs to learn to detect and analyse linguistic sounds and also develop an auditory memory. In fact, we can speak a foreign language well only if we can hear it properly. This paper presents an example of performative teaching and learning consisting of a musical activity for the foreign language lesson. Through music, foreign language learning can become a stimulating and creative experience in a cooperative and communicative atmosphere.
\end{abstract}

\section{Introduction}

Modern teaching approaches such as CLIL and various European policies (Council of Europe 2014) promote the vision of a multilingual school where the new European citizen can grow up learning at least two languages besides their mother tongue(s). From the point of view of foreign language teaching, especially interesting is the use of the arts (theatre, drama, music, dance, and fine arts), whether to create a new approach to teaching and learning (Schewe 2013) or to increase the motivation and commitment of the learners (Fleming 2014). In order for schools and teachers to be able to make use of the performing arts and modify their teaching methods accordingly, however, it will be necessary for government bodies and universities to modify and enrich teacher education - not just initial education but also continuing education with special courses, workshops, and conferences. 


\section{The link between language and music}

Language and music are two worlds that are strongly interconnected. According to Patel (2008: 3), both of these worlds define us as human because both of them appear in every human society, no matter what other aspects of culture may be absent. Even the smallest, most isolated tribes, like the Pirahã in Brazil, have music and songs in abundance though their language may lack fixed linguistic terminology (Everett 2005). Music is a skill specific to human beings: we are unparalleled in our ability to make sense out of sounds. Although we can learn much from studying the behaviour of animals because we have other experiences - such as perception and vision - in common with them, when it comes to music and language our species is unique. Music and language share numerous things, as they activate the use of the ear and the voice. In addition, both music and speech have a syntactic structure that can be represented using graphical symbols.

What have psychology and neuroscience discovered about the connection between these two worlds? Psychological research suggests possible cognitive benefits of formal musical training (Hannon \& Trainor 2007), and Piro \& Ortiz (2009) posit a relationship between musical training and linguistic ability. A link between music and language has been proposed for language education in order to account for the similarities between musical perception ability and language development (Anvari et al. 2002), and a certain amount of overlap has been noted in the brain regions responsible for processing music and those for processing language (Koelsch \& Siebel 2005).

Music is frequently regarded as an effective tool for improving memory. For example, music is commonly used in advertising as a strategy to boost retrieval (Stewart 1998). Wallace (1994) found that when subjects were presented with unfamiliar ballad excerpts, they achieved higher recall when the texts were sung than when they were spoken, and he deduced that melody acted to bind new text to itself, leading to a deeper level of encoding, thereby facilitating recall.

In light of the above, activities involving sound and music offer the foreign language teacher the opportunity to boost motivation and help students improve cognitive skills.

\section{Alfred Tomatis: the connection between voice and hearing}

The ear and the ability to listen play a very important role in foreign language learning. Alfred Tomatis, a French physician, developed an interesting method ${ }^{1}$ for education the way we listen using hearing and listening (1993). He

\footnotetext{
${ }^{1}$ The method encompasses sound sensory stimulation, that "operates on the plasticity of the neural circuits involved in the decoding and analysis of sounds, as well as on those involved in motricity, balance and coordination." (http://www.tomatis.com)
} 
discovered that many vocal problems, as well as dyslexia or learning disorders, were really hearing problems. Working with opera singers, he found that in the case of some singers, the power of their singing voice had damaged the muscles of their own middle ears because it surpassed their ears' endurance, reaching a volume of 130 decibels. As a result, these singers began forcing their voices to produce sounds in registers that they could no longer hear. He expressed his theory - known as the "Tomatis Effect" - in these important principles (Maule et al. 2006: 37-38):

- The voice does not produce what the ear does not hear;

- If the hearing is modified, the voice is immediately and unconsciously modified;

- It is possible to transform phonation in a lasting way if auditory stimulation is maintained over a certain amount of time.

The theory, or the "Tomatis Effect", is based on the principle that listening develops before birth. From the first period of pregnancy, the foetus begins to hear the rhythm and the melody of the mother's voice, which will influence his/her language skills and behaviour. Why is the theory of Tomatis important for the foreign language teacher? Tomatis believed that we can only speak a foreign language well if we can hear it properly, and to do that we must be able to distinguish the language's rhythms, sounds, and be aware of its musicality. The problem with learning a foreign language, however, is that most of us can only recognise the rhythms, sounds, and musicality of our mother tongue. The following table (Fig. 1) shows the different sound frequencies utilised by various languages (Maule et al. 2007: 33).

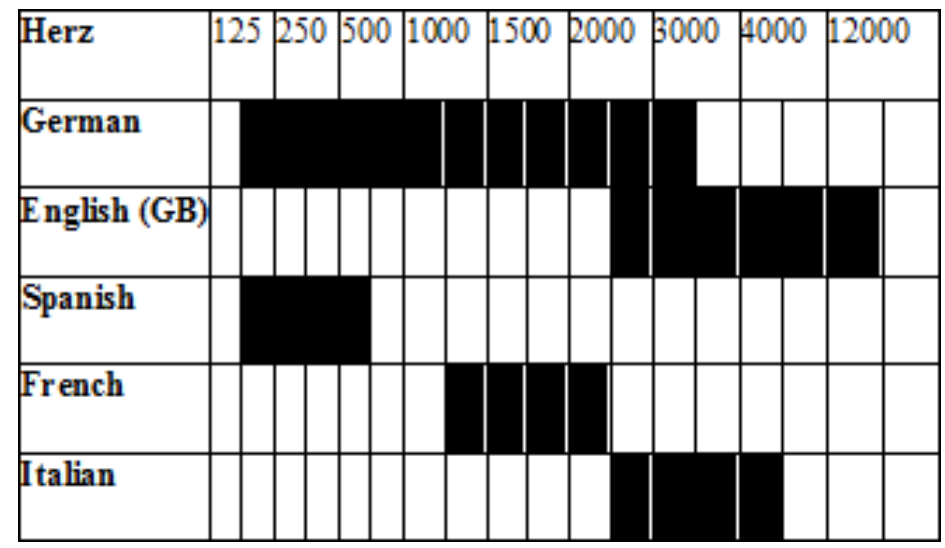

Figure 1: Fig. 1. Language sound frequencies

Every language makes use of a variety of sound frequencies, rhythms, and intonations. In order to speak a foreign language well we must be able to tune in to the sounds of that language. For example, since the Italian language lacks quite a few of the sounds used in German, e.g., those lying in the range between 
125 and 2,500 Hz, an Italian student of German will need to enhance his linguistic ear in order to be able to hear German correctly. In foreign language lessons, therefore, teachers should place more emphasis on developing this ability in students, and this can be done by providing certain kinds of activities on a daily basis.

\section{Sounds and music in foreign language teaching and learning}

There are a wide variety of musical activities that the teacher can incorporate into a foreign language class. Research in this area has demonstrated the effectiveness of a number of different options: action songs, words with rhythms, listening activities, songs, and stories with sounds (Maule et al. 2006).

The musical activities most commonly used by teachers in foreign language lessons are undoubtedly action songs (in the case of children) and other songs (with teenagers and adults). Action songs consist of vocal music that students can sing or perform with gestures, or else of instrumental music and sounds that can be used, for example, as support for a reading or as a learning motivator. Other songs are usually used with teenagers to make easier the vocabulary's imitation and retention, but also to practice listening skills. There are indeed different musical activities that the teacher can choose in order to improve the learning process.

Among these activities, one of the most interesting is to have students construct musical/sound objects. Each type of object would correspond to a specific sound-related word and reproduce the corresponding sound, e.g., a balloon with some rice placed inside it could be shaken to sound like waves on the sea. The sound objects could be created from discarded materials: bottles, cans, paper, buttons, boxes, strings, leaves, sand, rice, etc. With such sound objects it is possible for the teacher to work actively with a given text. The first step is to read the text, with the students and the teacher identifying some key words for which sound objects will be created. This is an excellent pedagogical activity because students work in groups, understand a text globally, memorise vocabulary through sounds, and work together in an interactive way. Furthermore, creating musical/sound objects boosts creativity and improves both manual skills and linguistic skills.

\section{A "performative" weather forecast}

The following activity was carried out in English with a primary-school class in Rome consisting of Italian-speaking eight-year-old students, spread out over four 60-minute lessons. The goals of the activity were to 1) learn and practice weather-related English vocabulary introduced by the teacher, 2) listen for and recognise key words in a text, and 3) create sound objects. During the first lesson the students read the text (Fig. 2), the teacher explained the meaning of 
any new words, and students worked together to find seven key words related to the weather (snowy, rain, windy, sunny, storms, thunder, hail). In the second lesson the sound corresponding to each of these key words was identified and a related sound object was created, e.g.:

- Wind: Take an empty bottle and blow into it.

- Rain: Make small holes in the bottom of a plastic yogurt container, beneath the container place a bowl with some water in it, then fill the container with water until water begins to fall through the holes.

- Thunder: Place some corks inside an empty bottle and shake the bottle.

- Snow: Cut some strips of plasticised paper and wave them in the air.

- Hail: Place rice inside an empty bottle and shake the bottle.

- Storm: Place some rice or pebbles inside a balloon, inflate the balloon and shake it

During the third and fourth lessons the class decided how to apportion the roles among themselves and rehearsed: two students were announcers (A) who read the text, six were sound makers, and six more were reporters from various countries (R1-R6). Some additional objects were used for the activity: the announcers spoke from inside a television (a large cardboard box with one side cut out of it) using microphones (pens), while each reporter wore an object that varied according to the weather of the nation that he/she was reporting from (e.g., for snow a scarf, for rain an umbrella). At the end the students put on a performance. 


\begin{tabular}{|c|c|}
\hline & Sonorization \\
\hline \multicolumn{2}{|l|}{$\begin{array}{l}\text { A: Good evening. Welcome to the World Weather Forecast. } \\
\text { Let's take a look at the weather now. }\end{array}$} \\
\hline \multicolumn{2}{|l|}{ (name) what's the weather like in Canada? } \\
\hline R1: Hello from Ottawa. Today it's cold and snowy. & paper strips \\
\hline \multicolumn{2}{|l|}{ A: Thank you! __ what's the weather like in France? } \\
\hline R2: Hello from Paris. Today it's overcast and rain is possible. & yoghurt tub \\
\hline \multicolumn{2}{|l|}{ A: Thank you! __ what's the weather like in Russia? } \\
\hline R3: Hello from Moscow. Today it's really windy. & bottle \\
\hline \multicolumn{2}{|l|}{ A: Thank you! __ what's the weather like in Italy? } \\
\hline R4: Hello from Rome. Today it's hot and sunny. & $\begin{array}{l}\text { a student says: "oh } \\
\text { yes!" }\end{array}$ \\
\hline \multicolumn{2}{|l|}{ A: Thank you! __ what's the weather like in England? } \\
\hline $\begin{array}{l}\text { R5: Hello from London. Today will be some severe storms } \\
\text { possible. }\end{array}$ & balloon \\
\hline \multicolumn{2}{|l|}{ A: Thank you! What's the weather like in Germany? } \\
\hline $\begin{array}{l}\text { R6: Hello from Berlin. Today it's raining with thunder and } \\
\text { hail. }\end{array}$ & $\begin{array}{l}\text { yoghurt tub and } \\
\text { bottles }\end{array}$ \\
\hline $\begin{array}{l}\text { A: And that's the World Weather Forecast for tonight. Thank } \\
\text { you and see you soon. }\end{array}$ & \\
\hline
\end{tabular}

\section{Conclusion}

While carrying out the above activity students displayed both intensified effort and interest. The opportunity to learn new vocabulary in a playful way, using the body, movements, and sounds, increased the motivation of every student who participated. Through this activity students also learned that conventional objects can be used in unconventional ways (e.g., a common bottle can be made to sound like the wind), and grasped how a traditionally-styled lesson can be transformed into a more "performative" lesson which takes the students' different learning styles into account and encourages everyone in the class, even disabled students who usually have difficulty to socialize with peers in English and to work in groups, to participate actively exercises of the kind I referred to above. 


\section{Bibliography}

Anvari, Sima H.; Trainor, Laurel K.; Woodside, Jennifer; Levy, Betty Ann (2002): Relations among musical skills, phonological processing and early reading ability in preschool children. In: Journal of Experiment Child Psychology 83, 111-130

Council of Europe (2014): Recommendation CM/Rec(2014)5 of the Committee of Ministers to member States on the importance of competences in the language(s) of schooling for equity and quality in education and for educational success. Strasbourg: Council of Europe

Everett, Daniel L. (2005): Cultural constraints on grammar and cognition in Pirahã: Another look at the design features of human language. In: Current Anthropology 46, 621-646

Fleming, Michael (2014): Language learning and the performing arts: issues of justification. In: Nofri, Carlo \& Stracci, Moreno (eds.): Performing Arts in Language Learning. Proceedings of the International Conference. Rome: Novacultur, 29-37

Hannon, Erin \& Trainor, Laurel (2007): Music acquisition: Effects of enculturation and formal training on development. In: Trends in Cognitive Sciences 11(11), 466-472

Koelsch, Stefan \& Siebel, Walter A. (2005): Towards a neural basis of music perception. In: Trends in Cognitive Science 9, 578-584

Maule, Elita; Cavagnoli, Stefania \&Lucchetti, Stefania (2006): Musica e apprendimento linguistico. Bergamo: Junior

Maule, Elita; Bertacchini, Carla \& Viel, Massimiliano (2007): Parole, suoni e musiche. Bergamo: Junior

Patel, Aniruddh D. (2008): Music, language and the brain. Oxford: Oxford University Press

Piro, Joseph \& Ortiz, Camilo (2009): The effect of piano lessons on the vocabulary and verbal sequencing skills of primary grade students. In: Psychology of Music 37(3), 325-347

Schewe, Manfred (2013): Taking Stock and Looking Ahead: Drama Pedagogy as a Gateway to a Performative Teaching and Learning Culture. In: Scenario VII(1), 5-28

Stewart, David W. (1998): Effects of using a nonverbal (musical) cue on recall and playback of television advertising: Implications for advertising tracking. In: Journal of Business Research 42, 39-51

Tomatis, Alfred (1993): Dalla Comunicazione intrauterina al linguaggio umano. Como: Ibis

Wallace, Wanda T. (1994): Memory for music: Effect of melody on recall. In: Journal of Experimental Psychology 20(6), 1471-1485 